\title{
An Exonic Splicing Enhancer in Human IGF-I Pre-mRNA Mediates Recognition of Alternative Exon 5 by the Serine-Arginine Protein Splicing Factor-2/ Alternative Splicing Factor
}

\author{
PHILIP J. SMITH, EMMA L. SPURRELL, JOHN COAKLEY, CHARLES J. HINDS, \\ RICHARD J. M. ROSS, ADRIAN R. KRAINER, AND SHERN L. CHEW
}

\begin{abstract}
Department of Endocrinology (P.J.S., E.L.S., R.J.M.R., S.L.C.), and Department of Anaesthesia and Intensive Care (J.C., C.J.H.), St. Bartholomew's Hospital, Queen Mary, University of London, London EC1A 7BE, United Kingdom; and Cold Spring Harbor Laboratory (A.R.K.), Cold Spring Harbor, New York 11724
\end{abstract}

The human IGF-I gene has six exons, four of which are
alternatively spliced. Variations in splicing involving exon
5 may occur, depending on the tissue type and hormonal
environment. To study the regulation of splicing to IGF-I
exon 5, we established an in vitro splicing assay, using a
model pre-mRNA containing IGF-I exons 4 and 5 and part of
the intervening intron. Using a series of deletion mutants,
we identified an 18-nucleotide purine-rich splicing en-
hancer in exon 5 that increases the splicing efficiency of the

M OST HUMAN GENES contain introns, which must be excised, and the exons spliced together, to allow gene expression. A substantial number of genes make transcripts that undergo alternative splicing, generating a great number of protein isoforms (1). The regulation of alternative splicing has been studied in some cases, and involves the serine-arginine (SR) family of splicing proteins and several heterogeneous nuclear RNA protein (hnRNPs) (2-4). Human IGF-I is a 70-residue peptide with growth-promoting and metabolic actions. It is derived from a gene with six exons, four of which are subject to alternative splicing (Fig. 1A). The alternative splices generate different precursor peptides, although they do not alter the structure of the mature peptide. Exons 1 and 2 are alternative leader exons derived from different transcription start sites, and encode part of the signal peptide $(5,6)$. Exons 3 and 4 are constant. Exons 5 and 6 are subject to a complex alternative splicing pattern. Exon 4 usually splices to exon 6 (5), but sometimes it splices to exon 5, representing $1-10 \%$ of IGF-I transcripts (7). A minor isoform results from splicing of exons 4 and 5, and from an alternative $5^{\prime}$ splice site in exon 5 to exon 6 (8).

The production of IGF-I isoforms in several species is regulated at transcriptional (9-11), posttranscriptional (8, $12-19)$ and translational $(20,21)$ levels. Once translated, the variant N-terminal domains encoded by IGF-I exons 1 or 2 are processed by canine microsomes, suggesting both are functional signal peptides (21). Alternative exons 5 and 6

Abbreviations: GAPDH, Glyceraldehyde phosphate dehydrogenase; hnRNP, heterogeneous nuclear RNA protein; ICU, intensive care unit; nt, nucleotides; SF2/ASF, splicing factor-2/alternative splicing factor; $\mathrm{SR}$, serine-arginine. upstream intron from 6 to $35 \%$. We show that the serinearginine protein splicing factor-2/alternative splicing factor specifically promotes splicing in cultured cells and in vitro and is recruited to the spliceosome in an enhancerspecific manner. Our findings are consistent with a role for splicing factor-2/alternative splicing factor in the regulation of splicing of IGF-I alternative exon 5 via a purine-rich exonic splicing enhancer. (Endocrinology 143: 146-154, 2002) encode different $\mathrm{E}$ domains. Part of the E domain encoded by exon 5 contains an amidated growth-promoting peptide (22), but there are few other functional data (23). Despite the lack of experimental data on the functional significance of the isoforms, there is species conservation of the genomic architecture of the exons, the splicing patterns producing alternative isoforms (6), and the peptide sequences (Cook, A., and S. L. Chew, manuscript in preparation). Because alternative splicing of exon 5 may vary depending on tissue type $(13,24$, $25)$ or hormonal environment $(8,12-14,17,26)$, we examined the mechanisms controlling splicing of this exon.

\section{Materials and Methods \\ Construction of pre-mRNA templates}

A model in vitro splicing system was established to examine splicing between IGF-I exons 4 and 5 (Fig. 1). The entire exon 4 is 182 nucleotides (nt), the intron is $1505 \mathrm{nt}$, and exon 5 is $218 \mathrm{nt}$ (up to the most upstream of several polyadenylation/cleavage sites). The experimental system involved incubation of radiolabeled IGF-I pre-mRNA substrates in HeLa nuclear extracts, followed by an assay of splicing. A major constraint of this approach is that RNA substrates splice less efficiently and are prone to degradation if they are too long. Therefore, for in vitro splicing experiments, we used only the downstream 93 nt of exon 4 and deleted a substantial part of the intron between exon 4 and exon 5 (Fig. 2A). This template, called SP6-IGF4-5, was made by overlap-extension PCR with Pfu Turbo (Stratagene, La Jolla, CA) and contains the SP6 RNA polymerase promoter to allow in vitro transcription of the IGF4-5 premRNA. Derivatives were made from SP6-IGF4 -5 with deletions of exon 5: pre-mRNAs A, B, and C (Fig. 2A) and E, F, and G (Fig. 3A). The derivatives were also made by PCR with $P f u$ Turbo. For making the SP6-IGF4-5 template, primers SP6-E4-493S (5'-ATTTAGGTGACACTATAGGGCTGGAGATGTATTGCGCA) and IGF-INT4-1599A (5'CCACCCACATGCACAAGAGAGAGA) were used to make a fragment containing $93 \mathrm{bp}$ of exon 4 and $63 \mathrm{bp}$ of the upstream intron. Primers 


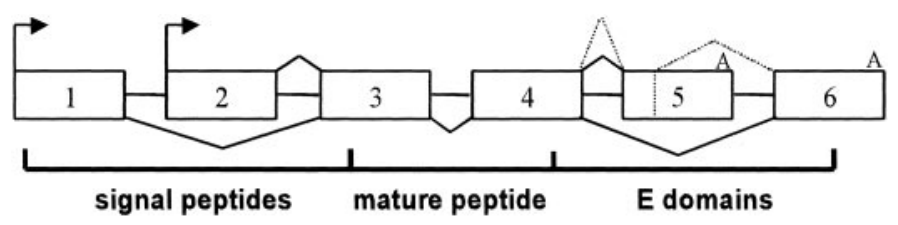

FIG. 1. Alternative splicing of the human IGF-I pre-mRNA. Exons are shown as boxes, introns as lines, transcription start sites as arrows, splicing patterns as sloped lines, and polyadenylation signals as the letter A. The protein-coding potential of the exons is indicated underneath.

OL-IGF-INT4-2809S (5'-TGCATGTGGGTGGCTCTTCCCAGGTGACCCA) and E5-557A (5'-CCTTGCCTCTGTCTGTTTAAT) were used to make a fragment containing $221 \mathrm{bp}$ of the $3^{\prime}$ end of the downstream intron and $218 \mathrm{bp}$ of exon 5. A third PCR, using SP6-E4-493S and E5-557A, in the presence of both amplified fragments, assembled the template. The product was cloned into pCR-blunt (Invitrogen, Carlsbad, CA) and verified by sequencing. Templates for in vitro transcription were made by further PCRs using a primer to the SP6 promoter and the following downstream primers: E5-630A (5'-TCCTTCTCTGAGACTTCG) for pre-mRNA A; E5-699A (5'-CTCTGATCTGCAGACTTGCT) for pre-mRNA B; E5-543A (5'-GTTTAATCCTCCTGTCCTTCA) for premRNA C; E5-557A for pre-mRNA D; E5-648A (5'-GTGTCTTTGGCCAACCTT) for pre-mRNA E; E5-666A (5'-TCTGTTCCCCTCCTGGAT) for pre-mRNA F; and E5-684A (5'-TTGCTTCTGTCCCCTCCT) for pre-mRNA G. All labeled pre-mRNAs were made with SP6 RNA polymerase using $\left[\alpha{ }^{32} \mathrm{P}\right]-\mathrm{GTP}$ and gel-purified. The $\mathrm{H} \beta \delta 6$ template has been described (27).

\section{Splicing reactions}

Splicing reactions were performed using $20 \mathrm{fmol}$ of pre-mRNA incubated at $30 \mathrm{C}$ with $48 \%$ HeLa nuclear or S100 cytosolic extract, $0.5 \mathrm{~mm}$ ATP, $3.2 \mathrm{~mm} \mathrm{MgCl}_{2}, 2.6 \%$ polyvinyl alcohol and $60 \mathrm{~mm} \mathrm{KCl}$. HeLa S100 extracts were prepared as described (28). Nuclear extracts were purchased from the Computer Cell Culture Center (Mons, Belgium). Twenty picomoles of human recombinant SF2/ASF [expressed in and purified from Escherichia coli (29)] or SC35 (expressed in baculovirus; a gift from R. Xu) was preincubated in the S100 extract before the complementation reaction. Intermediates and products of the splicing reactions were phenol-extracted and run on 5.5\% polyacrylamide gels before autoradiography. Quantification was done by digital photography of the autoradiograph with a Kodak DC210+, followed by analysis with the IMAGE program (Scion, Frederick, MD).

\section{Immunoprecipitations}

The antibody to SF2/ASF, mAb96, and control antibody to maltosebinding protein, $\mathrm{mAb} 105$, have been described (30). The antibody to hTra2 $\beta$ was kindly provided by Julian Venables and Ian Eperon (31). Immunoprecipitations were performed as described (32), with some changes. Briefly, splicing reactions were scaled up to $100 \mu \mathrm{l}$ and incubated for $2 \mathrm{~h}$, then diluted to $500 \mu \mathrm{l}$ with IP150 buffer ( $50 \mathrm{~mm}$ Tris- $\mathrm{HCl}$, $\mathrm{pH} 8.0 ; 150 \mathrm{~mm} \mathrm{NaCl} ; 0.05 \% \mathrm{NP} 40)$. Antibodies were pre-bound to protein A-Sepharose (Fast Flow, Amersham Pharmacia Biotech, Little Chalfont, Buckinghamshire, UK) in IP150 buffer and then added to splicing reactions and incubated at $4 \mathrm{C}$ for $1 \mathrm{~h}$, before three quick washes in IP150 buffer containing $0.5 \mathrm{mg} / \mathrm{ml}$ tRNA. The pellet was resuspended in $10 \mathrm{~mm}$ Tris- $\mathrm{Cl} \mathrm{pH} 8.0$ and $0.1 \mathrm{~mm}$ EDTA, and immunoprecipitated RNA recovered by phenol extraction and ethanol precipitation. The supernatant from the anti-MBP tubes was ethanol precipitated, and 10\% of the resuspended material was loaded as a control.

\section{Cotransfections and RNA analyses}

An IGF-I minigene containing exons 4, 5, and 6 (pEGFP-IGF-F1) was made. A PCR fragment containing exon 4 (171 bp), intron 4 (1505 bp), exon 5 up to the first polyadenylation/cleavage site $(218 \mathrm{bp})$ and the $5^{\prime}$ end of intron 5 (198 bp) was made with primers EcoRI-MOD4-2244S (5'-GGAATTCCGGGTATGGCTCCAGCAGT) and NotI-MODINT3238A (5'-ATAAGAATGCGGCCGCACATATATTGACATAGGCAATTCT) using Expand High Fidelity polymerase (Roche Molecular Biochemicals, Mannheim,
A

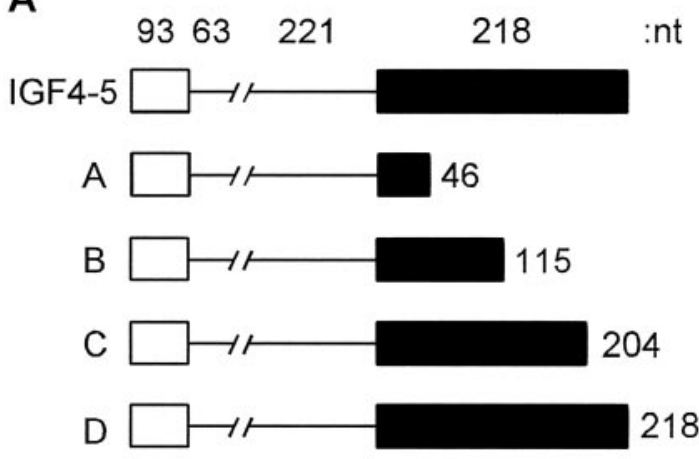

B

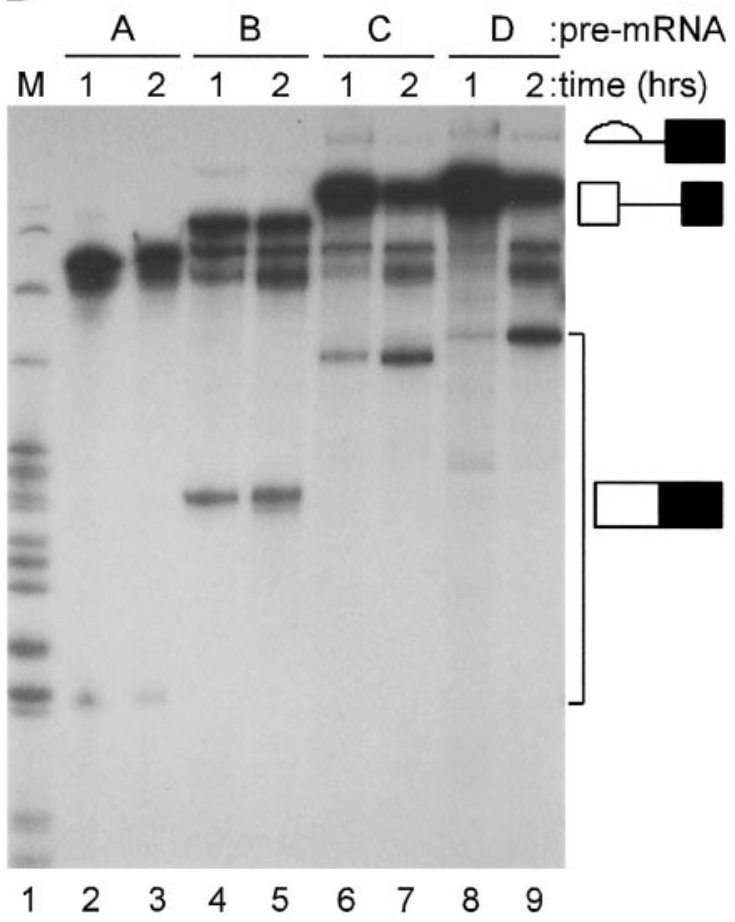

FIG. 2. In vitro splicing of IGF-I minigene transcripts with progressive deletions of exon 5. A, Diagrams of the pre-mRNAs used in in vitro splicing experiments. The splicing substrate IGF4-5 is shown, exon 4 as an open box, the intron as a line and exon 5 as a black box. The deletion of $1221 \mathrm{nt}$ from the intron is represented as double diagonal lines. The sizes in nucleotides (nt) are marked above the diagram. The deletion mutants, $\mathrm{A}, \mathrm{B}$, and $\mathrm{C}$ of exon 5 are shown underneath. The length of the $3^{\prime}$ exon is given after each deletion. B, Splicing reactions using IGF4-5 pre-mRNAs. The radiolabeled pre-mRNA substrates represented in Fig. 2A (and as indicated by letters above the lanes) were incubated in HeLa nuclear extracts for 1 or $2 \mathrm{~h}$ (as shown above the lanes). The reactions were deproteinized, RNA extracted and run on denaturing polyacrylamide gels. The identity of the pre-mRNA, intron-lariat, and mRNA bands is indicated by symbols on the right of the autoradiograph, with the mRNAs also indicated by the square bracket.

Germany) to amplify human genomic DNA. A second PCR fragment containing the $3^{\prime}$ end of intron 5 (284 bp) and exon 6 (399 bp) was made with primers NotI-MODINT3367S (5'-ATAAGAATGCGGCCGCATAGAAGCAGATGAATCAACT) and SacII-MOD6A (5'-GCTGAGCCGCGGAGTGCAACTGGATCTATACAA). The fragments were assembled via the NotI sites and cloned into the EcoRI and SacII sites of pEGFP-C1 (CLONTECH Laboratories, Inc., Palo Alto, CA). The construction was verified by sequencing on both strands and was used as 
A

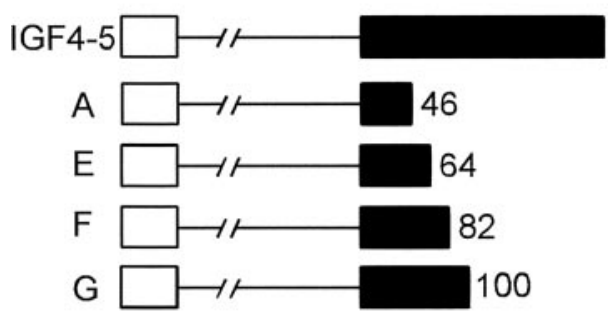

B

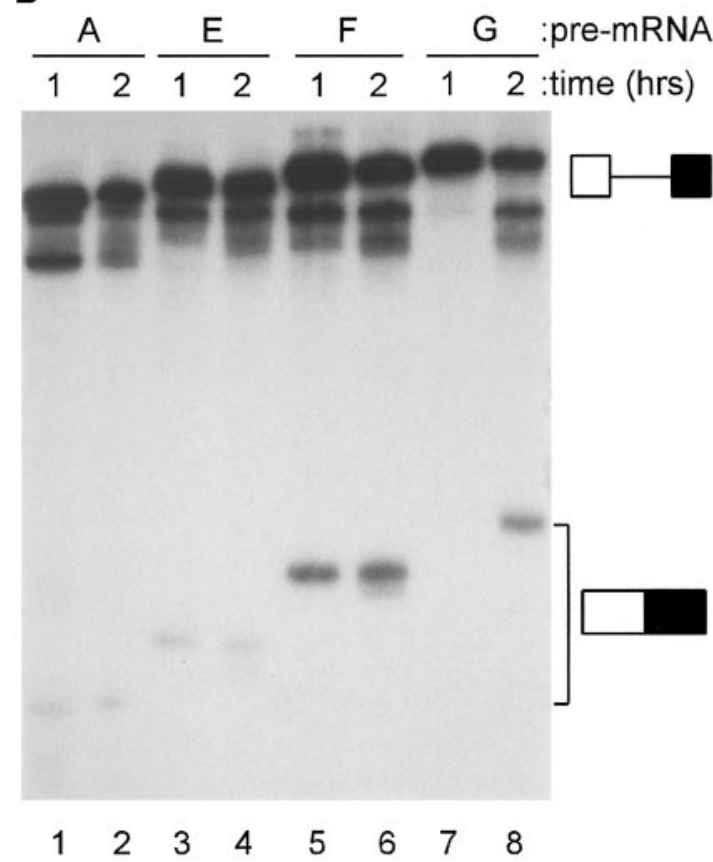

C

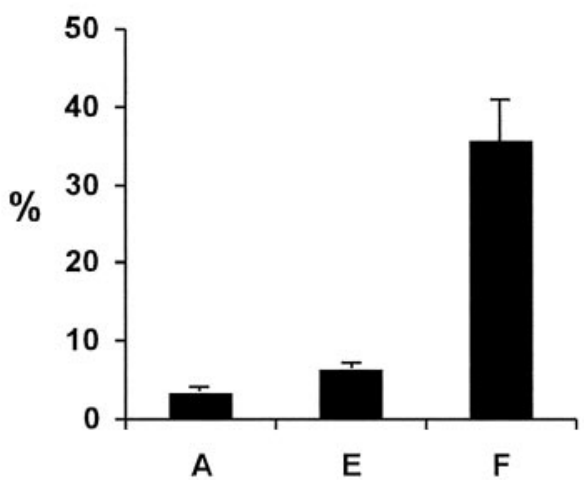

Substrate

FIG. 3. Fine deletion mapping of the exon 5 enhancer by in vitro splicing. A, Diagram of finer deletions of IGF4-5, pre-mRNAs E, F, and G, is shown, with sizes of the $3^{\prime}$ exons indicated in nucleotides at the end of the exon. B, Splicing reactions were performed by incubating the pre-mRNAs in nuclear extracts and products run on gels The premRNAs used and times of incubation are shown above the lanes. The identity of the pre-mRNA and mRNA bands is indicated by the symbols on the right of the gel, with mRNAs also indicated by a square bracket. $\mathrm{C}$, Quantification of splicing efficiencies. The y-axis shows the ratio of mRNA to pre-mRNA expressed as a percentage; the $\mathrm{x}$-axis indicates the identity of the pre-mRNAs; error bars represent SE $(\mathrm{n}=3)$. a reporter in cotransfection experiments (33) with plasmids pCG-SF2 (expressing SF2/ASF) or pCG-SC35 (expressing SC35). Briefly, $2 \mu \mathrm{g}$ of pEGFP-IGF-F1, with or without $2 \mu \mathrm{g}$ of pCG-SF2 or pCG-SC35, was transfected into approximately $75 \%$ confluent HeLa cells plated in $3-\mathrm{cm}$ diameter wells using Fugene 6 (Roche Molecular Biochemicals), according to the manufacturer's protocol. Total RNA was harvested $24 \mathrm{~h}$ later using the TRI reagent (Sigma, St. Louis, MO), and RT-PCR was performed as described (8). Splicing to exon 5 was assayed with primers EGFP-1323S (5'-GTACAAGTCCGGACTCAGAT) and E5-557A (5'CCTTGCCTCTGTCTGTTTAAT). Splicing to exon 6 was assayed with primers EGFP-1323S and E6-669A (5'-CTGCGGTGGCATGTCACTCTT). Reaction products were resolved on $6 \%$ nondenaturing polyacrylamide gels, photographed and scanned with a Scanjet 5370C (Hewlett-Packard Co., Palo Alto, CA) and quantified through the IMAGE program. Muscle biopsies were obtained from patients after written informed consent or assent and approval of the study by the local research ethics committee and were subjected to RNA extraction, RTPCR, Southern blotting and quantification, as described (8). Serum IGF-I was assayed by an in-house RIA (normal range 108-369 ng/ml; interassay and intraassay coefficient of variation $<10 \%$ ).

\section{Results \\ Splicing of IGF-I exon 5 in vitro}

We first constructed an IGF-I splicing substrate consisting of exons 4 and 5 and the entire intervening intron. This pre-mRNA was very unstable under standard in vitro splicing conditions (data not shown). We therefore made another IGF-I pre-mRNA substrate with a 1221-bp deletion in the intron, IGF4-5 (Fig. 2A). The construct was made by overlap extension PCR. The size and position of the deletion was designed to allow sufficient intronic sequence so that disruption of the splice sites was unlikely, but not too much to make the pre-mRNA difficult to manipulate or subject to degradation. In particular, the branchsite of the intron has not been mapped, so a longer section at the $3^{\prime}$ end of the intron was retained. This substrate spliced in vitro with little degradation (Fig. 2B, lane 9). We then generated a deletion series from the $3^{\prime}$ end of exon 5 (Fig. 2A). The initial deletions were large and designed to examine regions of exon 5 for elements affecting splicing efficiency. An increase in splicing efficiency between pre-mRNAs A and B was observed (Fig. 2B, compare lanes 2 and 3 with lanes 4 and 5). Substrates $C$ and $\mathrm{D}$ gave clear spliced products at $2 \mathrm{~h}$ (lanes 7 and 9), but the kinetics of mRNA appearance was slower than B at $1 \mathrm{~h}$ (compare lanes 6 and 8 to lane 4).

To define elements within the 69-nt segment between A and $\mathrm{B}$, this region was subdivided into three segments (E, F, and G; Fig. 3A). A significant improvement in splicing efficiency was seen between $E$ and $F$ pre-mRNAs (compare lanes 4 and 6; Fig. 3B), but not between $\mathrm{A}$ and $\mathrm{E}$ pre-mRNAs (compare lanes 2 and 4, Fig. 3B). In three independent experiments, the mean ratio of mRNA to pre-mRNA after 1 and $2 \mathrm{~h}$ of splicing increased from $3 \%$ (SE $0.5 \%$ ) and 6\% (SE 1\%) for pre-mRNAs A and E to 35\% (SE 5\%) for pre-mRNA F (Fig. 3C) $(P=0.02$, Kruskal-Wallis test). The sequence between pre-mRNA E and F is 18-nt long and purine-rich (ATCCAGGAGGGGAACAGA) and begins 64 nt downstream of the $3^{\prime}$ splice site of exon 5 and $15 \mathrm{nt}$ downstream of the alternative $5^{\prime}$ splice site in exon 5. Further enhancement of splicing was not achieved by sequences downstream of this element, and some delay in the kinetics of the reactions was seen with pre-mRNAs C, D, and G, suggesting the presence of silencer elements. 


\section{SF2 / ASF promotes splicing of IGF-I exon 5}

Several SR proteins in mammalian (34) and Drosophila (35) nuclear extracts bind purine-rich exonic elements to promote splicing. S100 cytosolic extracts were used to identify transacting factors required for promotion of splicing to exon 5 . These extracts are not competent for splicing because they lack SR proteins (36). We complemented S100 extracts with either of two recombinant SR proteins: SF2/ASF and SC35. Both SF2/ASF and SC35 were able to restore splicing of a $\beta$-globin pre-mRNA in an S100 extract (Fig. 4, lanes 3 and 4). We exploited this system to study the specificity of action of SR proteins on IGF pre-mRNA in vitro splicing. We incubated pre-mRNAs A, E, and F in nuclear and S100 extracts. As before, pre-mRNAs A and E showed only traces of splicing in nuclear extract (lanes 5 and 9), whereas pre-mRNA F was efficiently spliced (lane 13). None of the pre-mRNAs spliced in the S100 extract alone (lanes 2, 10, and 14; nonspecific degradation of the pre-mRNA is seen in lane 6). However, pre-mRNA F spliced efficiently in an S100 extract complemented with SF2/ASF (lane 15), but not in an S100 extract complemented with SC35 (lane 16). This indicated a specific requirement for SF2/ ASF and the purine-rich enhancer for in vitro splicing to IGF-I exon 5 and ruled out a nonspecific effect of exon length on splicing of the pre-mRNAs. SF2/ASF was unable to promote splicing of the IGF4 -5 pre-mRNA in the absence of this enhancer (lane 11). This experiment was independently performed twice with similar results.

\section{SF2 / ASF is recruited to the IGF-I pre-mRNA spliceosome} in an enhancer-specific manner

Tra2 is a Drosophila SR protein that regulates alternative splicing of Doublesex pre-mRNA via binding to nonpurinerich repeat elements and a purine-rich enhancer in Drosophila nuclear extracts and also when added to mammalian nuclear extracts. Drosophila Tra2 binds the exonic enhancers in a cooperative manner with SR proteins, including SF2/ASF (35). hTra $2 \alpha$ (37) and hTra2 $\beta$ (38) are human homologs of Tra2 and also promote sequence-specific splicing in mammalian pre-mRNA (39). To test whether similar cooperation may take place for the IGF-I enhancer, we assayed for the presence of SF2/ASF and hTra $2 \beta$ in the spliceosome by immunoprecipitations with anti-SF2/ASF and anti-hTra $2 \beta$. First, pre-mRNAs E and F were incubated in nuclear extracts for $2 \mathrm{~h}$. Next, specific antibodies were added to the reactions and immunoprecipitations were performed using protein A-Sepharose. If SF2/ASF or hTra $2 \beta$ are present in spliceosomes assembling on IGF pre-mRNAs, then spliceosomes and labeled pre-mRNA should be coimmunoprecipitated. The pellets containing labeled RNAs were deproteinized and the RNA run on polyacrylamide gels and visualized by autoradiography. The results showed that enhancer-containing pre-mRNA $F$ and mRNA were immunoprecipitated with anti-SF2/ASF or anti-hTra2 $\beta$ (Fig. 5, lanes 7 and 8), whereas only background levels were obtained with the control antiMBP antibody (lane 6). By contrast, in the absence of the enhancer, pre-mRNA E was immunoprecipitated at background levels only by anti-SF2/ASF (lane 3). Antibodies to hTra $2 \beta$ immunoprecipitated pre-mRNA E (i.e. in the absence of the enhancer) at levels higher than background (lane 4; and on overexposed blots, data not shown). This experiment was performed independently four times with similar results. We conclude that hTra $2 \beta$ is present in the IGF-I spliceosome, but not in an enhancer-dependent manner and it is unlikely that a cooperative interaction between SF2/ ASF and hTra $2 \beta$ occurs at the IGF-I enhancer.
FIG. 4. S100-complementation reactions with IGF4-5 substrates. Pre-mRNAs A, E, and F were incubated for $2 \mathrm{~h}$ in either nuclear extract (NE), or $\mathrm{S} 100$ extract (S100). Some S100 reactions were complemented with SR proteins SF2/ASF (SF2) or SC35. The extracts and SR proteins used in each reaction are indicated by + signs above the lanes. $\beta$-globin pre-mRNA $(\mathrm{H} \beta \delta 6)$ was used as a control in lanes $1-4$. The pre-mRNAs used are indicated above the lanes. The identity of the IGF pre-mRNA, lariatintermediate, lariat-product and mRNA bands are given on the right of the autoradiograph, with the mRNA bands also shown as a square bracket. The identity of the $\beta$-globin pre-mRNA, mRNA and $5^{\prime}$ exon intermediate bands is given on the left of the autoradiograph.

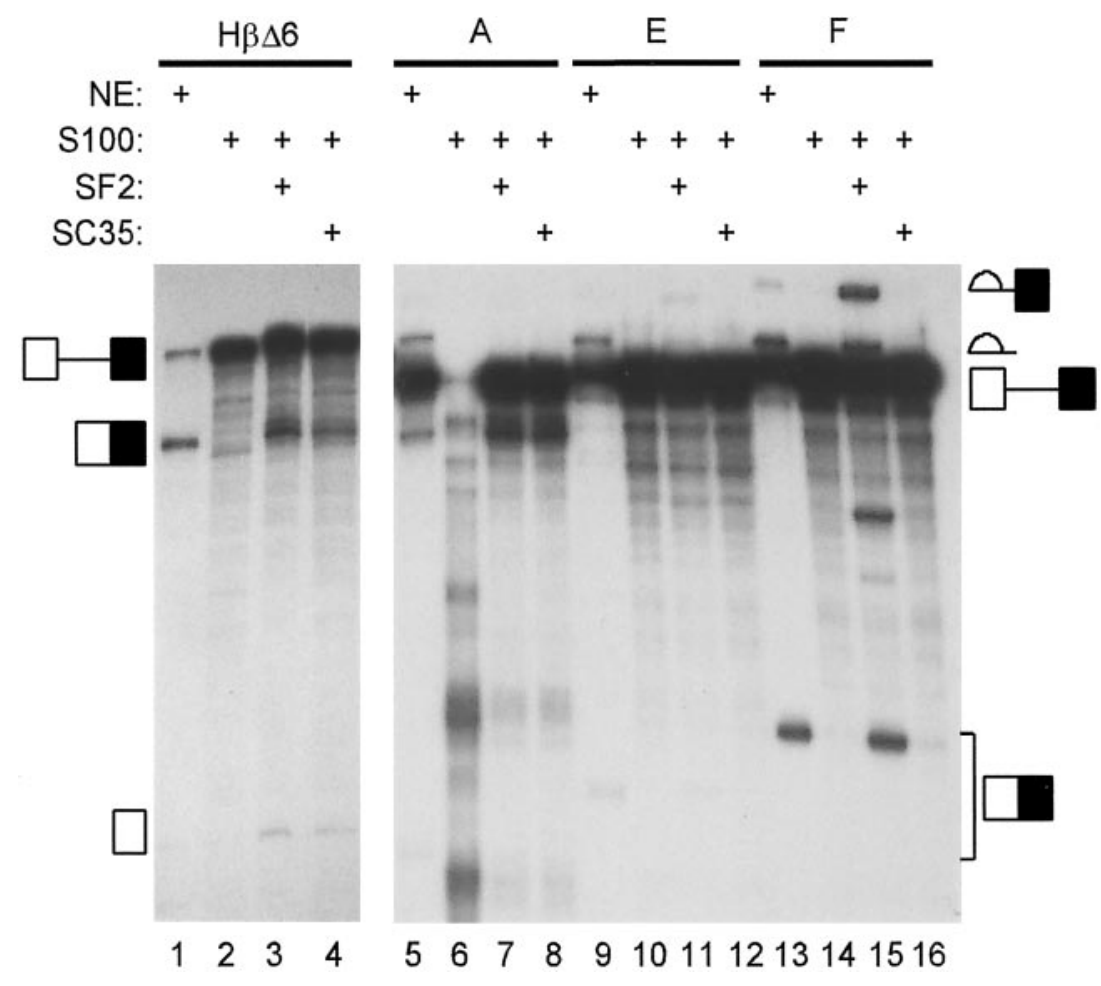




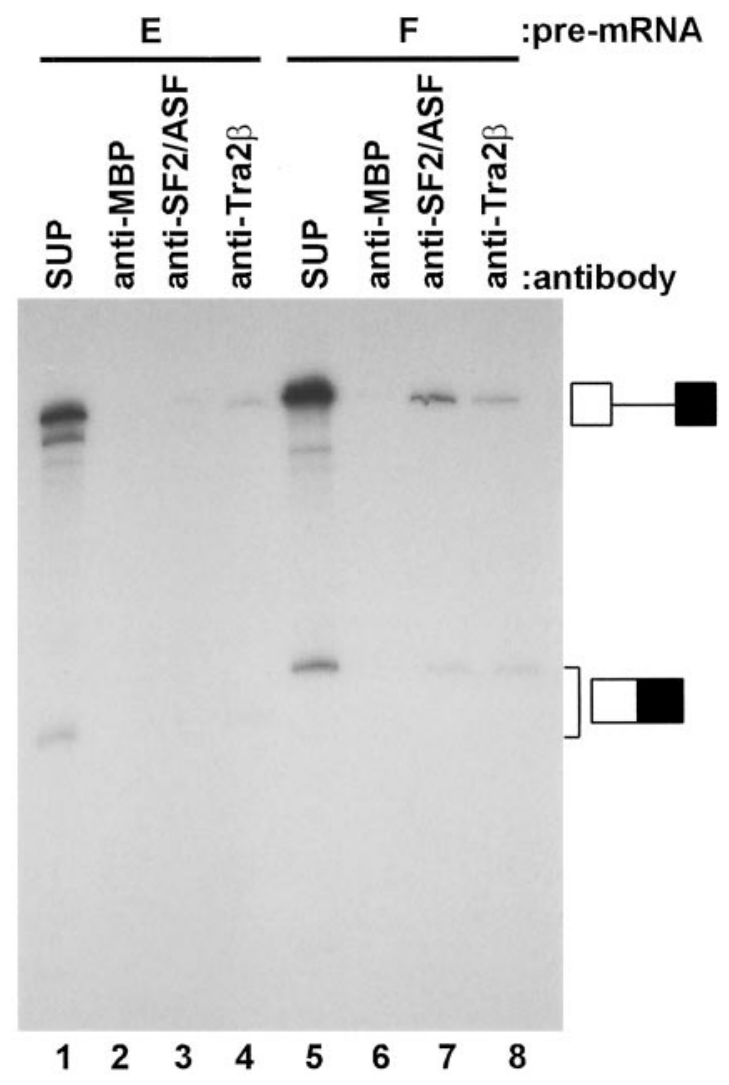

FIG. 5. Immunoprecipitation of labeled IGF-I transcripts from splicing reactions. Pre-mRNAs without $(\mathrm{E})$ or with $(\mathrm{F})$ the exon 5 enhancer element were incubated under splicing conditions. Prespliceosomal and spliceosomal complexes were immunoprecipitated with the indicated antibodies, and the labeled RNAs extracted from the precipitates. The lanes labeled SUP were loaded with $1 / 10$ of the RNA recovered from the supernatant of the control anti-MBP immunoprecipitations. The pre-mRNAs and antibodies used are indicated above the lanes. The identity of the pre-mRNA and mRNA bands is shown by symbols on the right of the gel.

\section{Overexpression of SF2/ASF in cultured cells promotes inclusion of exon 5}

To this point, experiments had been performed in vitro in a cell-free system. To show that regulation of splicing to IGF-I exon 5 was regulated by SF2/ASF in living cells, cotransfection experiments in cultured HeLa cells were performed. We designed and constructed an IGF-I minigene, pEGFPIGF-F1, in a eukaryotic expression plasmid. Note that this minigene was not subject to the same size limitations as the templates used for in vitro splicing and contained the entire intron between exons 4 and 5, and well as exon 6 and parts of the intron between exons 5 and 6. HeLa cells were transfected with pEGFP-IGF-F1 with or without cotransfection with plasmids expressing SF2/ASF (pCG-SF2) or SC35 (pCG-SC35). Splicing via exon 5 was very low in cells expressing the IGF-I minigene alone (Fig. 6A, lane 7), whereas splicing via exon 6 was clearly detected (lane 11). When SF2/ASF was over-expressed, splicing via exon 5 inclusion was promoted (lane 8 ), with a mean change of 4.7 -fold over three separate experiments $(P=0.004$, two-tailed $t$ test) (Fig. 6B). Overexpression of SC35 also promoted exon 5 inclusion, but less so (mean change of 3.6-fold; $P=0.03$ ). In vitro, SC35
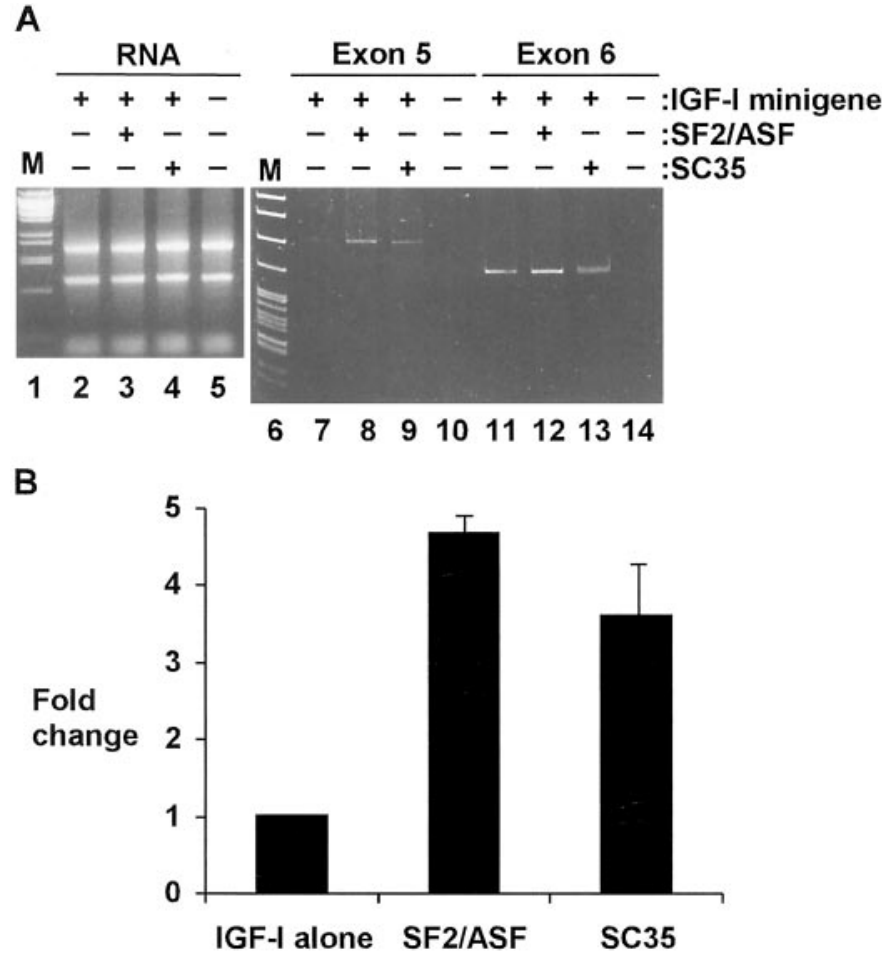

FIG. 6. Effect of transient overexpression of SF2/ASF or SC35 on alternative splicing of a cotransfected IGF-I minigene. A, The left panel shows total RNA from each well, as a control for recovery and loading. M, lambda/BstEII markers. The right panel shows representative data from an RT-PCR experiment. The exon amplified by each PCR reaction is indicated above the lanes. The + symbol above each lane indicates the plasmids used in transfections. M, pBR322/ MspI markers. B, Summary of data from three experiments showing the fold change of the ratio of exon 5 to exon 6 expression compared with the IGF-I minigene alone. Error bars represent SD.

did not promote splicing to exon 5 via the purine-rich sequence in pre-mRNA F (Fig. 4). Therefore, it is likely that the results in cultured cells reflect the additional exon 5 and downstream intronic sequences present in the minigene (not present in pre-mRNA F) and the presence of SC35-dependent enhancers in the additional sequences.

\section{Regulation of exon 5 inclusion in human muscle}

To investigate whether disordered expression of IGF-I may be implicated in clinical situations associated with muscle abnormalities, we examined the regulation of the IGF-I isoforms at the mRNA level in muscle biopsies available from studies of 20 patients. Ten patients had GH deficiency and muscle biopsies were performed at baseline, and repeated 6 months after GH treatment ( $n=5$ patients) or placebo treatment ( $n=5$ patients). Ten other patients were treated in an intensive care unit and had muscle biopsies at baseline and repeated 4 and $8 \mathrm{~d}$ later, as part of a study of intensive care unit (ICU)-related myopathy. IGF-I mRNAs containing exon 5 or 6 were measured by semiquantitative duplex RT-PCR using a glyceraldehyde phosphate dehydrogenase (GAPDH) PCR product as a standard.

In the group of patients with GH deficiency, GH-treated patients had increased relative IGF-I exon 5 levels (for representative data, see Fig. 7A, compare lane 1 with lane 2 and 


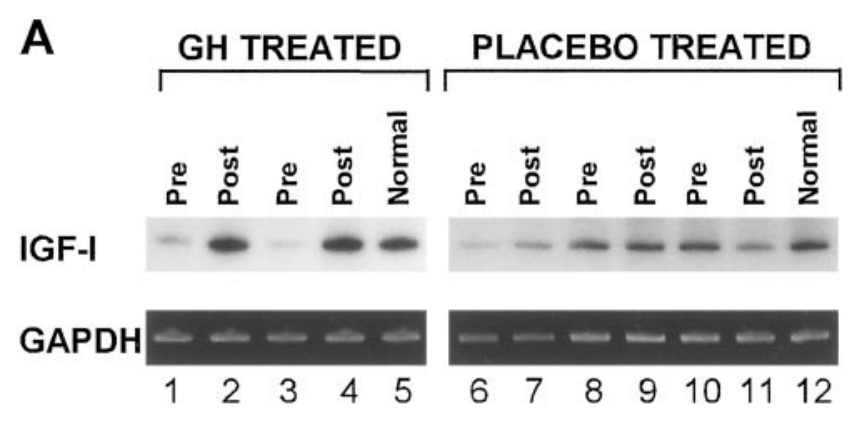

B

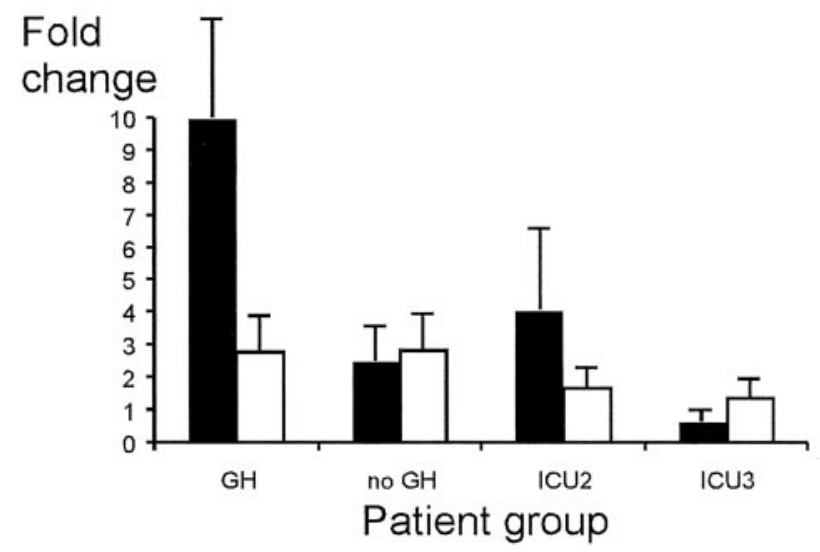

FIG. 7. A, IGF-I exon 5 inclusion in muscle biopsies from GH-deficient patients. Representative semiquantitative RT-PCR data for IGF-I exon 5 inclusion in muscle biopsies from GH-treated vs. placebotreated patients are shown in the top panel. GAPDH RT-PCR products were measured as an internal control, bottom panel. B, Relative level of IGF-I RT-PCR products from GH-deficient and ICU patients in follow-up muscle biopsies compared with baseline. The data are corrected for GAPDH expression and expressed as fold change from the baseline biopsy level. Solid bars show exon 5-containing products; open bars show exon 6-containing products; error bars are SE; GH, GH-treated; no GH, placebo-treated; ICU2, second biopsy from intensive-care patients; ICU3, third biopsy from intensive-care patients.

lane 3 with lane 4). Placebo-treated patients showed less marked changes in IGF-I exon 5 levels (lanes 6-11). As a group, GH-treated patients had a significant 10.0-fold increase (sE 2.9-fold) in relative inclusion of IGF-I exon 5 compared with baseline, compared with a 2.5 -fold increase in the placebo-treated patients (sE 1.1-fold) (Fig. 7B, solid bars; $P=$ 0.032 ; two-tailed $t$ test). Note that one patient in the GHtreated group, who showed no response by any criteria (including the serum IGF-I level, which failed to rise into the normal range) and who had a drop in muscle IGF-I exon 5 levels, was excluded from all analyses because we question the compliance of the patient with GH treatment. At baseline, there was no difference in age or body mass index between the GH-treated and the placebo-treated group (mean age 45 compared with 43.6 yr; mean body mass index 30 compared with $30.6 \mathrm{~kg} / \mathrm{m}^{2}$ ). The $\mathrm{GH}$-treated group were all male, whereas two of the five placebo-treated group were male. The increase in serum IGF-I levels after 6 months was significantly greater in the GH-treated compared with the placebo-treated group (mean rise in serum IGF-I of 441 vs. $45.4 \mathrm{ng} / \mathrm{ml} ; P=0.0003$; two-tailed $t$ test).
The patients in intensive care were heterogeneous with seven admitted after coronary or vascular surgery and three suffering severe sepsis. Four patients (including the three suffering sepsis) had clinical, electrophysiological, and histological evidence of myopathy. Five patients without clinical evidence of myopathy nevertheless had a drop in serum IGF-I levels to below the normal range from a mean of 138.2 $\mathrm{ng} / \mathrm{ml}$ falling to a mean of $85 \mathrm{ng} / \mathrm{ml}(P=0.018$; two-tailed paired $t$ test) by the time of the second biopsy. For one patient, no biochemical, electrophysiological, or histological data were available. In all the intensive care patients, the IGF-I mRNA expression patterns were unchanged (Fig. 7B). IGF-I exon 6-containing transcript levels were similar in all groups (Fig. 7B, open bars).

\section{Discussion}

A purine-rich exonic splicing enhancer in IGF-I exon 5 was identified by in vitro splicing assays with pre-mRNAs harboring systematic deletions in exon 5 . This enhancer functioned specifically with SF2/ASF, and overexpression of SF2/ASF in cultured HeLa cells promoted splicing via exon 5 inclusion. Splicing enhancer sequences have been identified in several regulated and constitutive exons, and may be classified into purine rich (40) and nonpurine rich (41). Enhancers interact with SR proteins, including SF2/ASF (35, 42-48). SF2/ ASF has high binding affinity for certain purinerich sequences in vitro (49) and, under splicing conditions, SF2/ASF and SC35 function through distinct and degenerate consensus sequences (50-52). We analyzed IGF-I exon 5 using matrices for predicting sequences through which SF2/ ASF and SC35 function $(50,52)$. The 18-nt extension between pre-mRNAs E and F significantly increases splicing to exon 5 . The extended sequence in the F pre-mRNA completes an SF2/ASF high-score heptamer motif (beginning at nt 60; Fig. 8) and adds yet another (beginning at nt 69). For SC35, the extension does not affect the number of high-score motifs present. The matrices show two high-score motifs for SF2/ ASF (beginning at nt 25 and 37) and two for SC35 (beginning at nt 5 and 53) in the part of exon 5 included in pre-

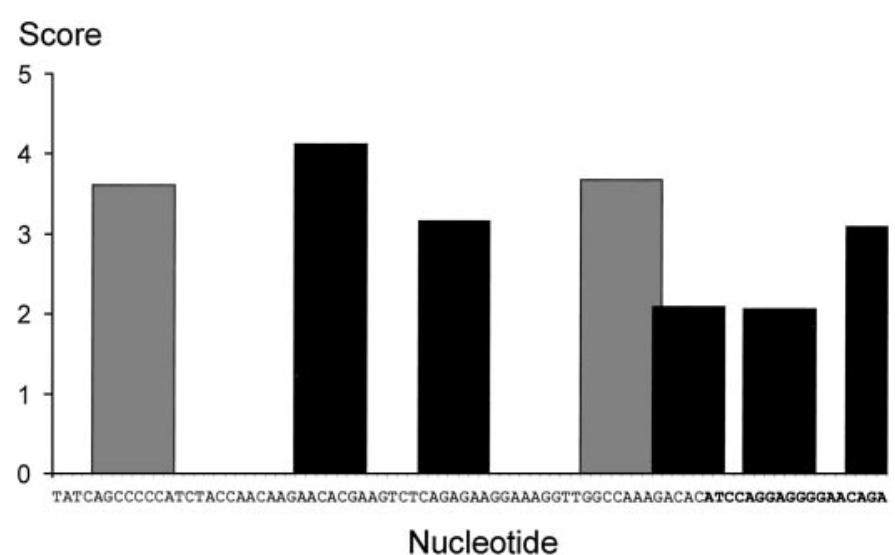

FIG. 8. High-score matches to SF2/ASF and SC35 consensus motifs in IGF-I exon 5. The nucleotides of exon 5 are given on the $\mathrm{x}$-axis and the score is on the y-axis. SF2/ASF scores are in black bars and SC35 in gray bars. The sequence extension in pre-mRNA F is shown in bold. Only motifs with scores above the previously defined thresholds of 1.956 for SF2/ASF and 2.383 for SC35 are shown (77). 
mRNA A. However, a score above threshold may not be sufficient for exonic splicing enhancer function, because of the surrounding context, e.g. a juxtaposed silencer, which we are currently unable to predict (52). Our data are compatible with IGF-I exon 5 being a substrate for SF2/ASF via a short enhancer element, and thus, this mechanism may underlie the control of splicing to this exon.

Another feature of the IGF-I exon 5 sequence is the presence of an alternative $5^{\prime}$ splice site contained in the last $18 \mathrm{nt}$ of pre-mRNA E. This site is used rarely in a tissue-specific manner in human liver (8) and is used in a human kidney tumor library (GenBank accession no. AI478804), although an equivalent site is commonly used in rodents and rabbits $(12,13,17)$. The presence of this site did not promote in vitro splicing to exon 5, nor was the site used for splicing when an IGF-I minigene was transfected into cultured HeLa cells. These data suggest that this site does not interact with U1 snRNP in HeLa extracts or cultured cells, perhaps due to the lack of a specific splicing activator or presence of an inhibitory factor, although the experiments reported here do not address this question.

We attempted to understand the regulation of IGF-I alternative splicing by examining human muscle biopsies taken during studies in patients with GH deficiency. There was a significant increase in the ratio of exon 5-containing mRNAs in patients after treatment with $\mathrm{GH}$, but not in those treated with placebo. The consequence of changes in splicing to exon 5 or 6 involves the E domain of the IGF-I precursor. The physiological roles of the E domains are unknown, although they are not present in insulin. The E domain encoded by exon 5 has been shown to harbor a mitogenic peptide fragment (22). Our preliminary experiments suggest the E domains may target the IGF-I precursor peptide to different cellular fates (unpublished data).

We also examined muscle biopsies from a heterogeneous group of intensive care patients, either with electrophysiological and histological evidence of myopathy, or with falls of serum IGF-I levels to below the normal range. GH resistance has been observed in such patients (53). In the intensive care patients, there was no trend evident in the ratios of muscle IGF-I mRNA isoforms. Our data make it less likely that changes in muscle IGF-I production play a role in ICU myopathy or in the falling IGF-I levels seen in these patients (53). It is possible that the fall in serum IGF-I in our patients was due to reduced liver production, as has been shown in rodent models (see references cited in 53) and by liverspecific IGF-I deletions in mice (54).

Several studies have investigated alternative splicing in the context of skeletal muscle differentiation, and in most cases this regulated expression involves exons that undergo skeletal muscle-specific inclusion or exclusion (e.g. in tropomyosin or troponin pre-mRNAs). Some of the factors regulating such exons are CUG-binding protein (55), SF2/ASF (56), and hnRNP H (57). The main difference between the skeletal muscle differentiation alternative splicing systems and our experiments is that muscle biopsies from the patients presumably represent fully differentiated tissue. Fully differentiated tissue may have a more limited capacity for changing splicing compared with that occurring during muscle differentiation. Also, both IGF-I isoforms are expressed, albeit with varying relative abundance. Thus, the effect of GH in changing IGF-I pre-mRNA splicing in differentiated adult skeletal muscle is quantitative. How the spliceosome is adapted to give qualitative changes in exon selection during muscle differentiation as well as quantitative changes seen in fully differentiated muscle is unclear.

SF2/ ASF binding promotes assembly of the splicing machinery (34) and later stages of the splicing reaction (58-61). In a well characterized system of alternative splicing, SF2/ ASF binds to the Drosophila doublesex purine-rich enhancer in a cooperative manner with Tra2 (35). hTra $2 \beta$ is one of two human homologs of Tra2 $(37,38)$ and promotes splicing in a sequence-specific manner (39). hTra2 $\beta$ binds a natural exonic splicing enhancer in a human $\alpha$ s tropomyosin alternative exon (Eperon, I. C., personal communication). In our experiments, hTra $2 \beta$ was present in the IGF-I spliceosome, but not in an enhancer-dependent manner. By contrast, SF2/ ASF associated with the spliceosome in an enhancer-dependent manner. This observation argues against simultaneous cooperative binding by SF2/ASF and hTra $2 \beta$ in the context of the IGF-I exon 5 enhancer but does not exclude the possibility that pre-bound hTra $2 \beta$ facilitates the recruitment of SF2 / ASF, or that SF2 / ASF binds cooperatively with other SR proteins or other RNA-binding proteins.

The activity of SF2/ASF may be regulated by several mechanisms $(34,62)$, including phosphorylation by kinases (63), cellular localization (64), and varying tissue concentrations (30). Some studies implicate SR proteins in signalingmediated changes in alternative splicing. Insulin signaling changes splicing involving rat fibronectin exon EIIIB and is associated with increased levels of HRS, the rat homolog of SRp40 (48). The alternative splicing response to serum stimulation or withdrawal in the mouse SRp20 pre-mRNA involves SF2/ASF and SRp20 $(65,66)$. Alternative splicing of CD44 and CD45 pre-mRNAs occurs during cytokineinduced T-cell differentiation, via PKC and Ras pathways (67-69). SC35, SF2/ASF and other SR proteins alter CD44 and CD45 splicing (70-72).

It is possible that SF2/ASF and the purine-rich enhancer are involved in pathways that control the relative levels of expression of IGF-I isoforms in different tissues $(13,24,25)$ and in response to GH in animal or cell culture models (8, $12-14,17,26)$, with some exceptions $(73,74)$. In vitro models for regulated splicing systems are difficult to develop (75), and hence it has not been possible to test whether SF2/ASF and the enhancer function in hormonally regulated or tissuedependent alternative splicing of IGF-I. However, there are examples of enhancers in other exons with dual function in promoting splicing both in constitutive and regulated contexts $(69,76)$. Our working hypothesis, derived from the present work in HeLa cells, is that alterations in the localization, phosphorylation or level of SF2/ASF by cellular signals, such as GH-stimulated pathways, may control IGF-I exon 5 inclusion via interaction with the purine-rich exonic element.

\section{Acknowledgments}

We are grateful to R. Xu and H.-X. Liu for SC35, A. Mayeda and L. Manche for help preparing SF2/ASF, J. Venables and I. Eperon for the anti-hTra $2 \beta$ antibody, J. Rodriguez-Arnao, G. Yarwood, C. Botfield, and 
G. M. Besser for the muscle biopsies, I. Eperon for helpful discussions and comments on the manuscript.

Received July 17, 2001. Accepted September 24, 2001.

Address all correspondence and requests for reprints to: Shern L. Chew, Department of Endocrinology, St. Bartholomew's Hospital, London EC1A 7BE, United Kingdom. E-mail: s.l.chew@mds.qmw.ac.uk.

S.L.C. was partly supported by the Wellcome Trust (045401), and A.R.K. was supported in part by NIH Grant GM-42699.

\section{References}

1. Black DL 2000 Protein diversity from alternative splicing: a challenge for bioinformatics and post-genome biology. Cell 103:367-370

2. Chabot B 1996 Directing alternative splicing: cast and scenarios. Trends Genet 12:472-478

3. Wang Y-C, Selvakumar M, Helfman DM 1997 Alternative pre-mRNA splicing. In: Krainer AR, ed. Eukaryotic mRNA processing. Oxford, UK: IRL Press; 242-279

4. Smith CW, Valcárcel J 2000 Alternative pre-mRNA splicing: the logic of combinatorial control. Trends Biochem Sci 25:381-388

5. Jansen M, van Schaik FMA, Ricker AT, Bullock B, Woods DE, Gabbay KH, Nussbaum AL, Sussenbach JS, Van den Brande JL 1983 Sequence of cDNA encoding human insulin-like growth factor I precursor. Nature 306:609-611

6. Tobin G, Yee D, Brunner N, Rotwein P 1990 A novel human insulin-like growth factor I messenger RNA is expressed in normal and tumor cells. Mol Endocrinol 4:1914-1920

7. Rotwein P 1986 Two insulin-like growth factor I messenger RNAs are expressed in human liver. Proc Natl Acad Sci USA 83:77-81

8. Chew SL, Lavender P, Clark AJL, Ross RJM 1995 An alternatively spliced human IGF-I transcript (IGF-IEc) with hepatic tissue expression that diverts away from the mitogenic IBE1 peptide. Endocrinology 136:1939-1944

9. Adamo ML, Ben-Hur H, Roberts CT, LeRoith D 1991 Regulation of start site usage in the leader exons of the rat insulin-like growth factor-I gene by development, fasting, and diabetes. Mol Endocrinol 5:1677-1686

10. Pell JM, Saunders JC, Gilmour RS 1993 Differential regulation of transcription initiation from insulin-like growth factor-I (IGF-I) leader exons and of tissue IGF-I expression in response to changed growth hormone and nutritional status in sheep. Endocrinology 132:1797-1807

11. Shemer J, Adamo ML, Roberts CT, LeRoith D 1992 Tissue-specific transcription start site usage in leader exons of the rat insulin-like growth factor-I gene: evidence for differential regulation in the developing kidney. Endocrinology 131:2793-2799

12. Roberts CTJ, Lasky SR, Lowe WLJ, Seaman WT, LeRoith D 1987 Molecular cloning of rat insulin-like growth factor I complementary deoxyribonucleic acids: differential messenger ribonucleic acid processing and regulation by growth hormone in extrahepatic tissues. Mol Endocrinol 1:243-248

13. Lowe Jr WL, Lasky SR, LeRoith D, Roberts Jr CT 1988 Distribution and regulation of rat insulin-like growth factor I messenger ribonucleic acids encoding alternative carboxyterminal E-peptides: evidence for differential processing and regulation in liver. Mol Endocrinol 2:528-535

14. Lowe Jr WL, Adamo ML, LeRoith D, Roberts Jr CT 1989 Expression and stability of insulin-like growth factor-I (IGF-I) mRNA splicing variants in the GH3 rat pituitary cell line. Biochem Biophys Res Commun 162:1174-1179

15. Hepler JE, Van Wyk JJ, Lund PK 1990 Different half-lives of insulin-like growth factor mRNAs that differ in length of $3^{\prime}$ untranslated sequence. Endocrinology 127:1550-1552

16. Duguay SJ, Swanson P, Dickhoff WW 1994 Differential expression and hormonal regulation of alternatively spliced IGF-I mRNA transcripts in salmon. J Mol Endocrinol 12:25-37

17. Yang S, Alnaqeeb M, Simpson H, Goldspink G 1996 Cloning and characterization of an IGF-1 isoform expressed in skeletal muscle subjected to stretch. J Muscle Res Cell Motil 17:487-495

18. Zhang J, Whitehead REJ, Underwood LE 1997 Effect of fasting on insulin-like growth factor (IGF)-IA and IGF-IB messenger ribonucleic acids and prehormones in rat liver. Endocrinology 138:3112-3118

19. Zhang J, Chrysis D, Underwood LE 1998 Reduction of hepatic insulin-like growth factor I (IGF-I) messenger ribonucleic acid (mRNA) during fasting is associated with diminished splicing of IGF-I pre-mRNA and decreased stability of cytoplasmic IGF-I mRNA. Endocrinology 139:4523-4530

20. Foyt HL, LeRoith D, Roberts Jr CT 1991 Effect of growth hormone on levels of differentially processed insulin-like growth factor I mRNA in total and polysomal mRNA populations. J Biol Chem 266:7300-7305

21. Yang H, Adamo ML, Koval AP, McGuinness MC, Ben-Hur H, Yang Y, LeRoith D, Roberts Jr CT 1995 Alternative leader sequences in insulin-like growth factor I mRNAs modulate translational efficiency and encode multiple signal peptides. Mol Endocrinol 9:1380-1395

22. Siegfried JM, Kasprzyk PG, Treston AM, Mulshine JL, Quinn KA, Cuttitta F 1992 A mitogenic peptide amide encoded within the E peptide domain of the insulin-like growth factor IB prohormone. Proc Natl Acad Sci USA 89:81078111
23. Lund PK, Hepler JE, Hoyt EC, Simmons JG 1991 Physiological relevance of IGF-I heterogeneity. In: Spencer EM, ed. Modern concepts of insulin-like growth factors. New York: Elsevier Science Publishing Co.;111-120

24. Hoyt EC, Van Wyk JJ, Lund PK 1988 Tissue and development specific regulation of a complex family of rat insulin-like growth factor I messenger ribonucleic acids. Mol Endocrinol 2:1077-1086

25. Nagaoka I, Someya A, Iwabuchi K, Yamashita T 1991 Expression of insulinlike growth factor-IA and factor-IB mRNA in human liver, hepatoma cells, macrophage-like cells and fibroblasts. FEBS Lett 280:79-83

26. Lin WW, Murray JD, Oberbauer AM 1998 Overexpression of growth hormone affects alternatively spliced IGF-I mRNA expression in oMt1a-oGH transgenic mice. Transgenic Res 7:295-302

27. Krainer AR, Maniatis T, Ruskin B, Green MR 1984 Normal and mutant human $\beta$-globulin pre-mRNAs are faithfully and efficiently spliced in vitro. Cell 36:993-1005

28. Mayeda A, Krainer AR 1998 Preparation of HeLa cell nuclear and cytosolic S100 extracts for in vitro splicing. Methods Mol Biol 118:309-314

29. Krainer AR, Mayeda A, Kozak D, Binns G 1991 Functional expression of cloned human splicing factor SF2: homology to RNA-binding proteins, U1 70K and Drosophila splicing regulators. Cell 66:383-394

30. Hanamura A, Cáceres JF, Mayeda A, Franza Jr BR, Krainer AR 1998 Regulated tissue-specific expression of antagonistic pre-mRNA splicing factors. RNA 4:430-444

31. Venables JP, Elliott DJ, Makarova OV, Makarov EM, Cooke HJ, Eperon IC 2000 RBMY, a probable human spermatogenesis factor, and other hnRNP $G$ proteins interact with Tra2 $\beta$ and affect splicing. Hum Mol Genet 9:685-694

32. Blencowe BJ, Nickerson JA, Issner R, Penman S, Sharp PA 1994 Association of nuclear matrix antigens with exon-containing splicing complexes. J Cell Biol 127:593-607

33. Cáceres JF, Stamm S, Helfman DM, Krainer A 1994 Regulation of alternative splicing in vivo by overexpression of antagonistic splicing factors. Science 265:1706-1709

34. Graveley BR 2000 Sorting out the complexity of SR protein functions. RNA 6:1197-1211

35. Lynch KW, Maniatis T 1996 Assembly of specific SR protein complexes on the distinct regulatory elements of the Drosophila doublesex splicing enhancer. Genes Dev 10:2089-2101

36. Krainer A, Conway GC, Kozak D 1990 Purification and characterization of pre-mRNA splicing factor SF2 from HeLa cells. Genes Dev 4:1158-1171

37. Dauwalder B, Amaya-Manzanares F, Mattox W 1996 A human homologue of the Drosophila sex determination factor transformer-2 has conserved splicing regulatory functions. Proc Natl Acad Sci USA 93:9004-9009

38. Beil B, Screaton G, Stamm S 1997 Molecular cloning of htra2- $\beta-1$ and htra2$\beta-2$, two human homologs of tra-2 generated by alternative splicing. DNA Cell Biol 16:679-690

39. Tacke R, Tohyama M, Ogawa S, Manley JL 1998 Human Tra2 proteins are sequence-specific activators of pre-mRNA splicing. Cell 93:139-148

40. Tian H, Kole R 1995 Selection of novel exon recognition elements from a pool of random sequences. Mol Cell Biol 15:6291-6298

41. Coulter LR, Landree MA, Cooper TA 1997 Identification of a new class of exonic splicing enhancers by in vivo selection. Mol Cell Biol 17:2143-2150

42. Hedley ML, Maniatis T 1991 Sex-specific splicing and polyadenylation of $d s x$ pre-mRNA requires a sequence that binds specifically to tra-2 protein in vitro. Cell 65:579-586

43. Sun Q, Mayeda A, Hampson RK, Krainer A, Rottman FM 1993 General splicing factor SF2/ASF promotes alternative splicing by binding to an exonic splicing enhancer. Genes Dev 7:2598-2608

44. Lavigueur A, La Branche H, Kornblihtt AR, Chabot B 1993 A splicing enhancer in the human fibronectin alternate ED1 exon interacts with SR proteins and stimulates U2 snRNP binding. Genes Dev 7:2405-2417

45. Ramchatesingh J, Zahler AM, Neugebauer KM, Roth MB, Cooper TA 1995 A subset of SR proteins activates splicing of the cardiac Troponin T alternative exon by direct interactions with an exonic enhancer. Mol Cell Biol 15:48984907

46. Gontarek RR, Derse D 1996 Interactions among SR proteins, an exonic splicing enhancer, and a lentivirus rev protein regulate alternative splicing. Mol Cell Biol 16:2325-2331

47. Yeakley JM, Morfin J-P, Rosenfeld MG, Fu X-D 1996 A complex of nuclear proteins mediates SR protein binding to a purine-rich splicing enhancer. Proc Natl Acad Sci USA 93:7582-7587

48. Du K, Peng Y, Greenbaum LE, Haber BA, Taub R 1997 HRS/SRp40-mediated inclusion of the fibronectin EIIIB exon, a possible cause of increased EIIIB expression in proliferating liver. Mol Cell Biol 17:4096-4104

49. Tacke R, Manley JL 1995 The human splicing factors ASF/SF2 and SC35 possess distinct, functionally significant RNA binding specificities. EMBO J 14:3540-3551

50. Liu H-X, Zhang M, Krainer AR 1998 Identification of functional exonic splicing enhancer motifs recognized by individual SR proteins. Genes Dev 12: 1998-2012

51. Schaal TD, Maniatis T 1999 Identification of functional exonic splicing enhancer motifs recognized by individual SR proteins. Mol Cell Biol 19:1705-1719

52. Liu H-X, Chew SL, Cartegni L, Zhang MQ, Krainer AR 2000 Exonic splicing 
enhancer motif recognized by human SC35 under splicing conditions. Mol Cell Biol 20:1063-1071

53. Ross RJM, Chew SL 1995 Acquired growth hormone resistance. Eur J Endocrinol 132:655-660

54. Butler AA, LeRoith D 2001 Minireview: Tissue-specific versus generalized gene targeting of the igf1 and igflr genes and their roles in insulin-like growth factor physiology. Endocrinology 142:1685-1688

55. Philips AV, Timchenko LT, Cooper TA 1998 Disruption of splicing regulated by a CUG-binding protein in myotonic dystrophy. Science 280:737-740

56. Gallego ME, Gattoni R, Stévenin J, Marie J, Expert-Bezançon A 1997 The SR splicing factors ASF/SF2 and SC35 have antagonistic effects on intronic enhancer-dependent splicing of the $\beta$-tropomyosin alternative exon 6A. EMBO J 16:1772-1784

57. Chen CD, Kobayashi R, Helfman DM 1999 Binding of hnRNP H to an exonic splicing silencer is involved in the regulation of alternative splicing of the rat $\beta$-tropomyosin gene. Genes Dev 13:593-606

58. Tarn WY, Steitz JA 1995 Modulation of 5' splice site choice in pre-messenger RNA by two distinct steps. Proc Natl Acad Sci USA 92:2504-2508

59. Roscigno RF, Garcia-Blanco MA 1995 SR proteins escort the U4/U6.U5 trisnRNP to the spliceosome. RNA 1:692-706

60. Chew SL, Liu H-X, Mayeda A, Krainer AR 1999 Evidence for the function of an exonic splicing enhancer after the first catalytic step of pre-mRNA splicing. Proc Natl Acad Sci USA 96:10655-10660

61. Zheng ZM, Quintero J, Reid ES, Gocke C, Baker CC 2000 Optimization of a weak $3^{\prime}$ splice site counteracts the function of a bovine papillomavirus type 1 exonic splicing suppressor in vitro and in vivo. J Virol 74:5902-5910

62. Manley JL, Tacke R 1996 SR proteins and splicing control. Genes Dev 10: 1569-1579

63. Misteli T 1999 RNA splicing: what has phosphorylation got to do with it? Curr Biol 9:R198-R200

64. Misteli T, Cáceres JF, Clement JQ, Krainer AR, Wilkinson MF, Spector DL 1998 Serine phosphorylation of SR proteins is required for their recruitment to sites of transcription in vivo. J Cell Biol 143:297-307

65. Jumaa H, Guenet J-L, Nielsen PJ 1997 Regulated expression and RNA pro- cessing of transcripts from the SRp20 splicing factor gene during the cell cycle. Mol Cell Biol 17:3116-3124

66. Jumaa H, Nielsen PJ 1997 The splicing factor SRp20 modifies splicing of its own mRNA and ASF/SF2 antagonizes this regulation. EMBO J 16:5077-5085

67. Screaton GR, Cáceres JF, Mayeda A, Bell MV, Plebanski M, Jackson DG, Bell JI, Krainer AR 1995 Identification and characterisation of three members of the human SR family of pre-mRNA splicing factors. EMBO J 14:4336-4349

68. Konig H, Ponta H, Herrlich P 1998 Coupling of signal transduction to alternative pre-mRNA splicing by a composite splice regulator. EMBO J 17:29042913

69. Lynch KW, Weiss A 2000 A model system for activation-induced alternative splicing of CD45 pre-mRNA in T cells implicates protein kinase $C$ and Ras. Mol Cell Biol 20:70-80

70. Lemaire R, Winne A, Sarkissian M, Lafyatis R 1999 SF2 and SRp55 regulation of CD45 exon 4 skipping during T cell activation. Eur J Immunol 29:823-837

71. ten Dam GB, Zilch CF, Wallace D, Wieringa B, Beverley PC, Poels LG Screaton GR 2000 Regulation of alternative splicing of CD45 by antagonistic effects of SR protein splicing factors. J Immunol 164:5287-5295

72. Wang HY, Xu X, Ding JH, Bermingham JR, Fu XD 2001 SC35 plays a role in T cell development and alternative splicing of CD45. Mol Cell 7:331-342

73. Bichell DP, Kikuchi K, Rotwein P 1992 Growth hormone rapidly activates insulin-like growth factor I gene transcription in vivo. Mol Endocrinol 6:18991908

74. Stahlbom AK, Sara VR, Hoeben P 1999 Insulin-like growth factor mRNA in Barramundi (Lates calcarifer): alternative splicing and nonresponsiveness to growth hormone. Biochem Genet 37:69-93

75. Chew SL 1997 Alternative splicing of mRNA as a mode of endocrine regulation. Trends Endocrinol Metab 8:405-413

76. Tian M, Maniatis T 1994 A splicing enhancer exhibits both constitutive and regulated activities. Genes Dev 8:1703-1712

77. Liu H-X, Cartegni L, Zhang MQ, Krainer AR 2001 A mechanism for exon skipping caused by nonsense or missense mutations in BRCA1 and other genes. Nat Genet 27:55-58 